\title{
Follow-up of Metal-on-Metal Hip Replacements at a Large District Hospital and the Implementation of Medicines and Healthcare Products Regulatory Agency Guidelines: A Review of 297 Patients
}

\author{
Luke Hughes, MRCS, Kathryn Chamberlain, PhD, Heather Robinson, MSc, \\ Andrew Sloan, FRCS, Qaisar Choudry, FRCS
}

Department of Trauma and Orthopaedics, Blackburn Royal Infirmary, Blackburn, UK

\begin{abstract}
Background: Medicines and Healthcare products Regulatory Agency (MHRA) guidance for patients with metal-on-metal (MoM) hip replacements was provided in 2012 and updated in 2017 to assist in the early detection of soft-tissue reactions due to metal wear debris. A large number of MoM hip replacements were undertaken at our hospital trust. A program of recall for all patients with MoM hip replacements was undertaken and MHRA guidelines were implemented. In this study, we aimed to investigate the effectiveness of the revised MHRA guidelines in the detection of early adverse reactions to metal debris and to re-evaluate the indications for metal artifact reduction sequence magnetic resonance imaging (MARS-MRI) and revision surgery.

Methods: Identification and recall of all patients with MoM hip replacements from 2001 were conducted by using theatre logs, patient records, clinical coding information, and consultant logbooks. Two senior arthroplasty consultants reviewed X-rays and patient records. Postal questionnaires were forwarded to patients, together with requests for general practitioners to complete cobalt and chromium blood tests. The two consultant-led review of MOM replacements was undertaken with further radiological investigations (X-rays, MARS-MRI) performed according to the 2017 guidance with support of consultant radiologists.

Results: Of 674 identified patients, 297 were available for review: 26 patients did not have MoM implants, 36 were untraceable, 59 refused follow-up, 87 moved out of area, 147 had died, and 22 already had revision. Of 297 patients, 126 were women and 171 were men; age range was 39 to 95 years (mean age, 69 years); 126 had resurfacing and 171 had MoM replacements. Twenty-six patients had elevated metal ions. Thirty-three patients underwent MARS-MRI: MARS-MRI results were positive in 17 and negative in 16. Of 17 patients with positive MARS-MRI, 10 patients were asymptomatic and seven were waiting revision.

Conclusions: Positive MARS-MRI can often occur in the absence of elevated metal ion levels; elevated blood metal ion levels do not mean MARS-MRI will be positive. All patients with MoM replacements were at risk. It is imperative to assess patients regularly for symptoms that may raise clinical suspicion and maintain a low threshold to performing MARS-MRI.
\end{abstract}

Keywords: Hip, Arthroplasty, Metal, Adverse, Monitoring

Received April 8, 2019; Accepted June 21, 2019

Correspondence to: Luke Hughes, MRCS

Department of Trauma and Orthopaedics, Blackburn Royal Infirmary, Haslingden Rd, Blackburn BB2 3HH, UK

Tel: +7487788778

E-mail:drlukehughes@hotmail.co.uk
As of 2018, the number of primary hip replacements recorded in the National Joint Registry was 992,090. ${ }^{1)}$ Of these, less than $1 \%$ comprised metal-on-metal (MoM) bearings, a sharp decline from the peak of MoM implants reaching $20 \%$ in 2005 . The principle behind the redevelopment of the MoM bearing couple in the 1990s was to reduce the wear rate, avoid osteolysis, and ultimately 
improve the longevity of bearing couples. Metal resurfacing maintains the normal anatomy of the proximal femur, whilst a large metal femoral head can increase the range of motion and reduce the risk of dislocation. However, despite these benefits, some patients with MoM bearing couples developed significant complications. Immune reactions to metal wear debris cause soft-tissue inflammatory reactions, such as metallosis, aseptic lymphocytic vasculitis-associated lesion (ALVAL) and pseudotumors, which together are grouped under the umbrella term, adverse reactions to metal debris (ARMDs). ${ }^{2)}$ These can have disastrous consequences for the patient. The progressive destruction of soft tissues causes pain, reduced mobility, osteolysis, implant loosening, fracture, and treatment failure.

Approximately $25 \%$ of MoM total hip replacements and $13 \%$ of MoM resurfacing operations will require a revision at 10 to 13 years. This is compared with metal-onpolyethylene implants, which are revised in less than $4 \%$ of cases at 10 years after insertion. ${ }^{1)}$ In 2010, the Medicines and Healthcare products Regulatory Agency (MHRA) published guidance to healthcare professionals on what action should be taken for those patients who had been fitted with MoM hip bearing couple articulations. ${ }^{3)}$ At that time, the advice was that all symptomatic patients and those asymptomatic patients with the DePuy ASR hip replacements (Johnson \& Johnson, New Brunswick, NJ, USA) or stemmed MoM total hip replacements with a femoral head size of $>36 \mathrm{~mm}$ should have an annual review. It was stated that the review should include symptomatic evaluation by way of the Oxford Hip Score assessment; blood tests to monitor circulating levels of chromium and cobalt ions; X-ray; and if deemed necessary, for assessment of bone and soft-tissue injury due to clinical concern, crosssectional imaging by way of metal artefact reducing (MAR) magnetic resonance imaging (MRI) or ultrasound. ${ }^{4)}$ The MHRA currently recommends seven parts per billion (ppb) for whole blood metal ion levels as the threshold for concern.

Updated guidance released in $2017^{5)}$ recommends

\section{Table 1. 2017 Updated Medicines and Healthcare Products Regulatory Agency Guidelines}

\begin{tabular}{|c|c|c|c|c|}
\hline Device implanted & $\begin{array}{l}\text { Hip resurfacing (no stem) } \\
\text { - Female } \\
\text { - Male (femoral head } \leq 48 \mathrm{~mm} \text { ) } \\
\text { - DePuy ASR hip resurfacing } \\
\text { devices } \\
\text { Stemmed THR } \\
\text { - Femoral head diameter } \geq 36 \mathrm{~mm}\end{array}$ & \multicolumn{3}{|c|}{$\begin{array}{l}\text { Hip Resurfacing (no stem) } \\
\text { Male (femoral head }>48 \mathrm{~mm} \text { ) } \\
\text { Stemmed THR } \\
\text { Femoral head diameter }<36 \mathrm{~mm} \\
\end{array}$} \\
\hline Patient and device group & Symptomatic and asymptomatic & Symptomatic & $\begin{array}{l}\text { Asymptomatic } \\
\text { - All stemmed THR } \\
\text { - Resurfacing devices } \\
\text { without } 10 \mathrm{~A} \text { ODEP rating }\end{array}$ & $\begin{array}{l}\text { Resurfacing devices } \\
\text { with } 10 A \text { ODEP rating }\end{array}$ \\
\hline $\begin{array}{l}\text { Frequency of follow-up } \\
\text { after primary operation date }\end{array}$ & $\begin{array}{l}\text { Annually while the device } \\
\text { remains implanted }\end{array}$ & $\begin{array}{l}\text { Annually while the } \\
\text { device remains } \\
\text { implanted }\end{array}$ & $\begin{array}{l}\text { Annually for the first } 5 \text { years, } \\
2 \text { yearly to } 10 \text { and } 3 \text { yearly } \\
\text { thereafter }\end{array}$ & $\begin{array}{l}\text { First year, once at } 7 \text { years } \\
\text { and } 3 \text { yearly } \\
\text { thereafter }\end{array}$ \\
\hline Questionnaire & Oxford Hip Score assessment & $\begin{array}{l}\text { Oxford Hip Score } \\
\text { assessment }\end{array}$ & $\begin{array}{l}\text { Oxford Hip Score } \\
\text { assessment }\end{array}$ & $\begin{array}{l}\text { Oxford Hip Score } \\
\text { assessment }\end{array}$ \\
\hline Imaging & $\begin{array}{l}\text { MARS MRI or ultrasound } \\
\text { recommended if negative } \\
\text { change in oxford hip score } \\
\text { and/or elevated/rising } \\
\text { blood metal levels is observed }\end{array}$ & $\begin{array}{l}\text { MARS MRI or ultrasound } \\
\text { in all cases }\end{array}$ & $\begin{array}{l}\text { - Plain radiographs } \\
\text { - MARS MRl or ultrasound } \\
\text { recommended if negative } \\
\text { change in oxford hip } \\
\text { score is observed and/ } \\
\text { or elevated/rising blood } \\
\text { metal levels }\end{array}$ & $\begin{array}{l}\text { - Plain radiographs } \\
\text { - MARS MRl or ultrasound } \\
\text { recommended if negative } \\
\text { change in oxford hip } \\
\text { score is observed and/ } \\
\text { or elevated/rising blood } \\
\text { metal levels }\end{array}$ \\
\hline Blood metal level test & All patients & All patients & All patients & All patients \\
\hline Consider need for revision & $\begin{array}{l}\text { If imaging is abnormal and/or } \\
\text { blood metal levels rise and/or } \\
\text { hip-related clinical function/ } \\
\text { Oxford Hip Score deteriorates }\end{array}$ & $\begin{array}{l}\text { If imaging is abnormal } \\
\text { and/or blood metal } \\
\text { levels rise and/or } \\
\text { hip-related clinical } \\
\text { function/Oxford Hip } \\
\text { Score deteriorates }\end{array}$ & $\begin{array}{l}\text { If imaging is abnormal and/ } \\
\text { or blood metal levels rise } \\
\text { and/or hip-related clinical } \\
\text { function/Oxford Hip Score } \\
\text { deteriorates }\end{array}$ & $\begin{array}{l}\text { If imaging is abnormal } \\
\text { and/or blood metal levels } \\
\text { rise and/or hip-related } \\
\text { clinical function/Oxford } \\
\text { Hip Score deteriorates }\end{array}$ \\
\hline
\end{tabular}

THR: total hip replacement, ODEP: Orthopaedic Data Evaluation Panel, MARS: metal artifact reduction sequence. 
Hughes et al. Follow-up of Metal-on-Metal Hip Replacements and Adherence to MHRA Guidelines

Clinics in Orthopedic Surgery • Vol. 11, No. 4, 2019• www.ecios.org

that surgeons should follow up all patients with MoM bearings regardless of symptoms (Table 1). The Orthopaedic Data Evaluation Panel (ODEP) 10A rating is awarded to those implants that have the highest quality data on outcomes with a minimum 10-year follow-up, which support their safe use. ${ }^{6}$

This study presents a method for implementing the MHRA guidelines at a large general district hospital. The results and outcomes of implementation are described together with a plan for continued patient surveillance. This study aims to investigate the effectiveness of the revised MHRA guidelines in the detection of early ARMDs and re-evaluate the indications for MRI metal artifact reduction sequence magnetic resonance imaging (MARS-MRI).

\begin{tabular}{|c|c|}
\hline 674 & $\begin{array}{l}\text { - Total number of patients identified from theatre logs } \\
\text { and patient records. }\end{array}$ \\
\hline 648 & $\begin{array}{l}26 \text { Determined not to undergo } \\
\text { metal-on-metal total hip arthroplasty. }\end{array}$ \\
\hline 612 & - 36 Untraceable. \\
\hline 553 & 59 Refused follow-up. \\
\hline 466 & . 87 Moved out of area. \\
\hline 319 & · 147 Had died. \\
\hline 297 & - 22 Already revised. \\
\hline
\end{tabular}

Fig. 1. Cohort details.

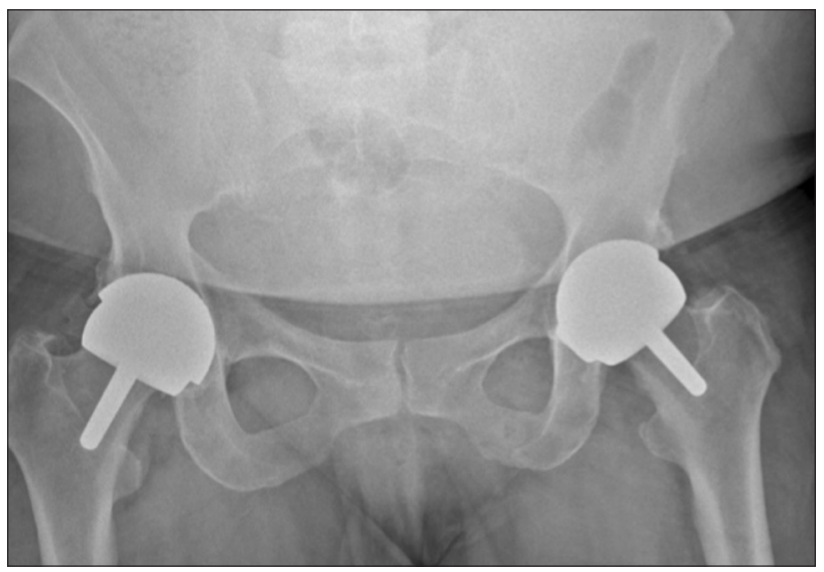

Fig. 2. Pelvis radiograph of a patient who had bilateral hip resurfacing.

\section{METHODS}

Patients with an MoM implant from 2001 onwards were identified by using theatre logs, patient records, clinical coding information, and consultant logbooks (Fig. 1). Two senior arthroplasty consultants (AS, QC) reviewed the Xrays and records for each patient to confirm the nature of the implant. Postal questionnaires were sent to all patients with MoM hip arthroplasty to document details of functional status and residual symptoms. General practitioners were recruited to obtain patient blood samples to assess and monitor cobalt and chromium ion blood levels. All patients were invited to attend a combined, consultantled review clinic. The MARS-MRI was performed in all patients with either elevated metal ions or clinical indications (pain, reduced mobility, palpable mass, or suspicious radiological findings), or both, according to the 2017 guidance. Imaging results were reviewed in multidisciplinary team (MDT) with support of consultant radiologists. When MARS-MRI was positive for patients reviewed in the multidisciplinary clinic, further management was discussed.

\section{RESULTS}

A total of 297 patients were reviewed in the clinic. Of these, 126 were men and 171 were women. The age range was between 39 and 95 years with a mean age of 64 years. A total of 126 patients had hip resurfacing (Fig. 2) and 171 patients had stemmed MoM total hip arthroplasty (THR) (Fig. 3). The implants used for hip resurfacing included the Birmingham Hip Resurfacing (Smith \& Nephew) and Recap (Biomet). Implants for the stemmed THR were the Corin cup (Corin) and Zweymuller stem (Smith \& Nephew).

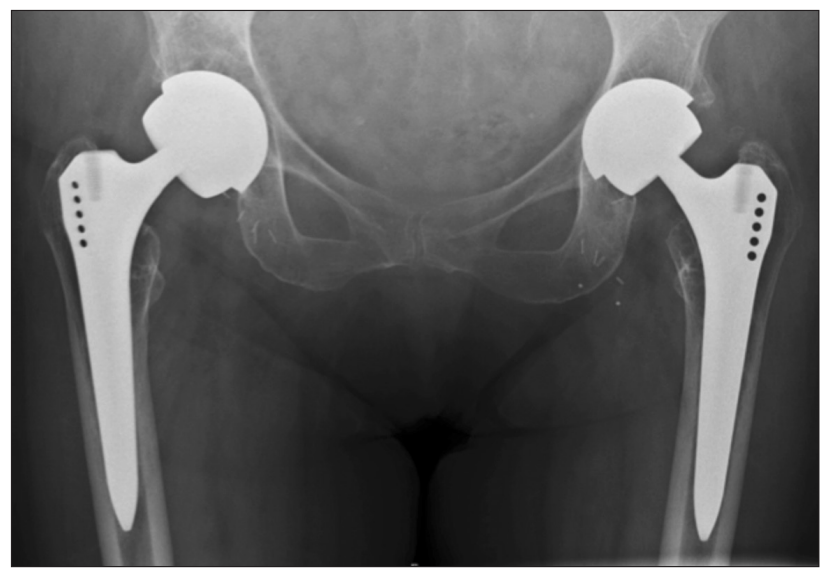

Fig. 3. Pelvis radiograph of a patient who had bilateral large-head metalon-metal total hip replacement. 
Hughes et al. Follow-up of Metal-on-Metal Hip Replacements and Adherence to MHRA Guidelines

Clinics in Orthopedic Surgery • Vol. 11, No. 4, $2019 \bullet$ www.ecios.org

X-rays failed to reveal any evidence of bone or softtissue destruction in any of the asymptomatic patients; subtle osteolysis and loosening were seen in a minor proportion of symptomatic patients. Blood metal ions were elevated in 26 patients. Thirty-three patients underwent MARS-MRI. Of these, 17 were positive (10 asymptomatic patients and seven patients awaiting revision); 16 were negative. When MARS-MRI was positive, this demonstrated tissue fluid only, with no evidence of bone destruction, fracture, or pelvic collection (Figs. 4 and 5). All asymptomatic patients with positive MARS-MRI met with a consultant in the multidisciplinary clinic to discuss the pros and cons of revision surgery versus close surveillance comprising 6-monthly clinic review, metal level monitoring, and 12-monthly MARS-MRI. To date, all asymptomatic patients chose surveillance. Of the patients who had positive MARS-MRI, five had hip resurfacing (one woman and four men); 12 had stemmed THR (four women and eight men; 11 large heads [> $36 \mathrm{~mm}$ ]).

Blood cobalt levels were elevated in three of the five resurfacing patients with positive MARS-MRI and ranged from 190.4 to $4,239.1 \mathrm{nmol} / \mathrm{L}$ (normal, $0-120 \mathrm{nmol} / \mathrm{L}$ ). Blood cobalt levels were elevated in six of the $12 \mathrm{MoM}$ THR patients with positive MARS-MRI and ranged from 129.0 to $395.0 \mathrm{nmol} / \mathrm{L}$. Blood chromium levels were elevated in three of the five resurfacing patients and ranged from 212.0 to $3,257.0 \mathrm{nmol} / \mathrm{L}$ (normal, $0-135 \mathrm{nmol} / \mathrm{L}$ ); in two of the $12 \mathrm{MoM}$ THR patients, $181.0 \mathrm{nmol} / \mathrm{L}$ and 314.0 nmol/L, respectively.

Of the patients with negative MARS-MRI, four

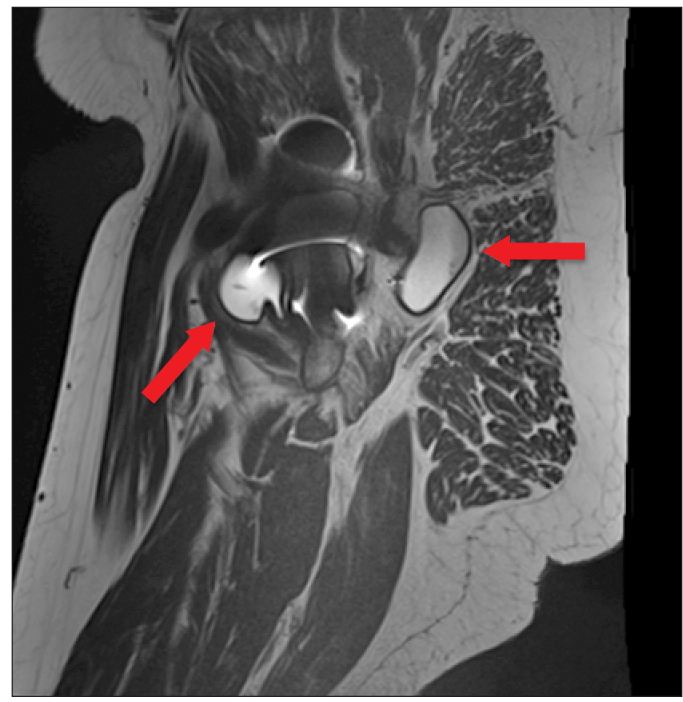

Fig. 4. T2-weighted magnetic resonance imaging with artifact reduction. Sagittal view of the right hip demonstrating significant periarticular fluid (white arrows). had hip resurfacing (two women and two men); 12 had stemmed THR (eight women and four men; all large heads [> $36 \mathrm{~mm}]$ ). Blood cobalt levels were elevated in none of the hip resurfacing patients with negative MARS-MRI and seven of the 12 MoM THR patients with negative MARSMRI and ranged from 124.5 to $263.1 \mathrm{nmol} / \mathrm{L}$. Blood chromium levels were elevated in none of the patients with negative MARS-MRI.

\section{DISCUSSION}

The ARMDs are destructive and can demonstrate a very gradual progression. They have been demonstrated to develop in patients that appear asymptomatic. ${ }^{7-9)}$ The links suggested between elevated blood metal ion concentration, a poorly functioning implant, metallosis, ALVAL, and pseudotumor formation ${ }^{10-13)}$ have previously supported blood sampling as a simple method of patient screening. The MHRA's upper acceptable limit for whole blood cobalt or chromium level is $7 \mathrm{ppb}$. This level has demonstrated a specificity of $89 \%$ and sensitivity of $52 \%$ for detecting a preoperative unexplained failure of a MoM hip replacement ${ }^{14)}$ However, this upper acceptable level is controversial, with Sidaginamale et al. ${ }^{15)}$ finding sensitivity and specificity with blood cobalt levels as low as $4.5 \mathrm{ppb}$. Currently there is no internationally agreed threshold for whole blood metal levels that either predict outcome or mandate revision.

Our results show that (1) positive MARS-MRI can often occur in the absence of elevated metal ion levels and

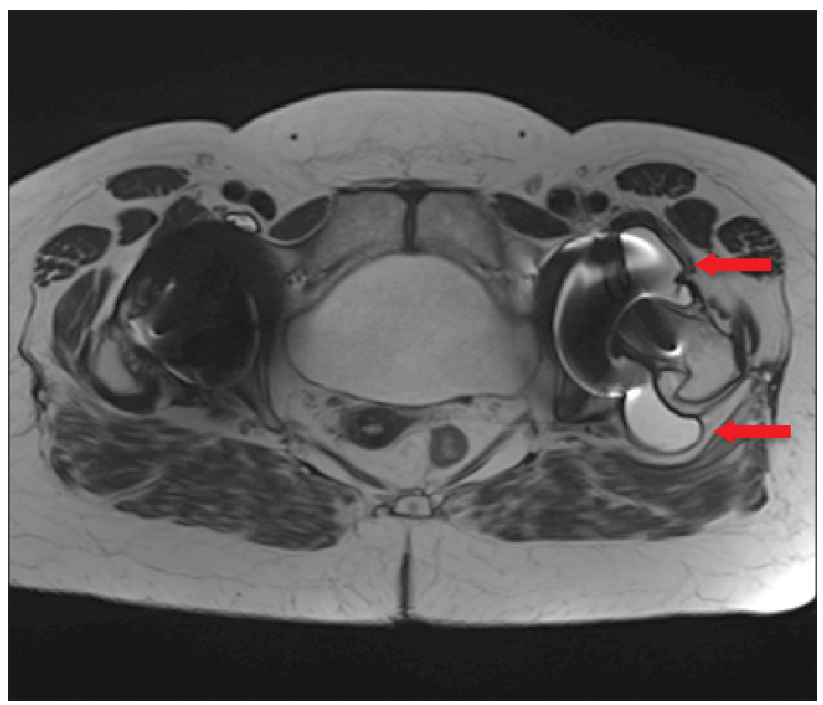

Fig. 5. T2-weighted magnetic resonance imaging with artifact reduction. Axial view of the right hip demonstrating significant periarticular fluid around the right hip (arrows) and no significant fluid around the left hip. 
(2) elevated metal ion levels do not necessarily mean that MARS-MRI will be positive and revision will be necessary. It is, therefore, imperative that patients be regularly assessed for symptoms that may raise clinical suspicion, in addition to metal ion level monitoring. Studies have supported the use of MARS-MRI, as an effective and noninvasive method of identifying soft-tissue reactions. ${ }^{16,17)}$ This has been supported in our study and there should be a low threshold to performing MARS-MRI in this cohort of patients.

With close monitoring, adverse reactions can be identified and managed early to avoid further deterioration that can complicate treatment. Research has demonstrated that women with femoral heads $>36 \mathrm{~mm}$ are at increased risk, ${ }^{18)}$ as are those without ODEP 10A-rated implants. However, these findings were not supported by our results, with men appearing to demonstrate a higher rate of ARMDs. By dividing patients into high and low risk, the MHRA guidelines encourage surgeons to maintain a high index of suspicion for those patients most at risk. ${ }^{3)}$ However, if these guidelines fail to correctly identify those at greatest risk, they can only serve to confuse and may lead to neglect of certain patient groups.

Initially, studies investigating the outcomes after revision surgery, owing to the complications of MoM THR, reported poor outcomes ${ }^{7,19,20)}$ However, a systematic review completed by Matharu et al. ${ }^{21)}$ in 2014 reported that research into outcomes after revision for ARMDs was of poor quality, comprising studies with limited sample size and missing data. Furthermore, they identified a lack of robust thresholds for performing revision surgery for ARMDs. This prompted further investigation with a later paper published in $2018^{22)}$ concluding that outcomes of revision surgery for ARMDs are improving with time. They postulated that this was facilitated by regular patient monitoring in accordance with the MHRA guidelines, coupled with a lower threshold for performing revision surgery. This means that patients with ARMDs are being identified and operated on earlier and that this is having a positive impact on outcomes.

This study investigated outcomes in a large patient cohort from a single general district hospital. Patient identification was a time-consuming effort, with additional resource and support of hospital trusts required to facilitate the recall of MoM patients. MARS-MRI was deemed necessary in $11.1 \%$ of patients. There was a positive re- sult in $5.7 \%$ of recalled patients. Considering the natural progression and potential impact of these complications, well-defined guidelines for monitoring are of significant importance. However, our results failed to support some of the parameters specified in the updated guidance of MHRA, particularly, the characteristics of those most at risk. We conclude that a high index of suspicion must be maintained for all patients. Although blood metal ion monitoring is a useful tool, its clinical relevance does have limitations. Yet there is no substitution for a thorough clinical examination.

After this large recall of patients, we have established a live database to enable follow-up and tracking of all patients with MoM hips. We have developed an arthroplasty practitioner-led clinic for review of MoM patients with clear pathways in accordance with the guidelines from MHRA/British Hip Society. Any patients alerting are then placed into an MDT clinic with two arthroplasty consultants and radiology support. The dilemma remains the asymptomatic patient with a longstanding MoM hip, normal radiology, normal or mildly raised metal ions, and only small traces around the prosthesis on MARS-MRI. In this scenario, we advocate the importance of MDT with two consultants' review and close monitoring.

The limitation of this study was the high loss to follow-up. This could be expected given the average age of patients and the period of time to follow-up. We noted 89 patients refused to attend follow-up. This group consisted of patients who had undergone their surgery many years earlier and had no obvious concerns regarding their hips, and despite being made aware of complications of MoM, they declined an invitation to follow-up. Attempts to look into this group further identified that most of these patients had either significant other comorbidities or were currently residing in nursing or care homes, or both.

On the basis of this work, we recognize the importance of being able to identify patients undergoing implant surgery and the role of implant registers to facilitate this. It is imperative that hospital trusts and consultants that have performed MoM hip replacements identify their patients and follow the MHRA guidance for follow-up.

\section{CONFLICT OF INTEREST}

No potential conflict of interest relevant to this article was reported. 


\section{REFERENCES}

1. HQIP. National joint registry for England, Wales, Northern Ireland and the Isle of Man: 15th annual report 2018. Hemel Hempstead: NJR Service Centre; 2018.

2. Watters TS, Cardona DM, Menon KS, Vinson EN, Bolognesi MP, Dodd LG. Aseptic lymphocyte-dominated vasculitisassociated lesion: a clinicopathologic review of an underrecognized cause of prosthetic failure. Am J Clin Pathol. 2010;134(6):886-93.

3. Medicines and Healthcare products Regulatory Agency. All metal-on-metal (MoM) hip replacements, health. London: Medicines and Healthcare products Regulatory Agency; 2012.

4. Berber R, Skinner JA, Hart AJ. Management of metal-onmetal hip implant patients: who, when and how to revise? World J Orthop. 2016;7(5):272-9.

5. Medicines and Healthcare products Regulatory Agency. All metal-on-metal (MoM) hip replacements: updated advice for follow-up of patients. London: Medicines and Healthcare products Regulatory Agency; 2017.

6. Pickford, M. ODEP rating: supporting innovation? Orthopaedic Data Evaluation Panel rating - supporting innovation [Internet]. Nottingham: Northgate Public Services (UK) Ltd.; 2013 [cited 2019 Sep 1]. Available from: http://www. odep.org.uk/ODEPExplained/toPatients.aspx.

7. Grammatopoulos G, Pandit H, Kwon YM, et al. Hip resurfacings revised for inflammatory pseudotumour have a poor outcome. J Bone Joint Surg Br. 2009;91(8):1019-24.

8. Liddle AD, Satchithananda K, Henckel J, et al. Revision of metal-on-metal hip arthroplasty in a tertiary center: a prospective study of 39 hips with between 1 and 4 years of follow-up. Acta Orthop. 2013;84(3):237-45.

9. Matharu GS, Ostlere SJ, Pandit HG, Murray DW. What is the natural history of asymptomatic pseudotumours in metal-on-metal hip resurfacing patients? Hip Int. 2016;26(6):522-30.

10. Hailer NP, Bengtsson M, Lundberg C, Milbrink J. High metal ion levels after use of the $\mathrm{ASR}^{\mathrm{TN}}$ device correlate with development of pseudotumors and T cell activation. Clin Orthop Relat Res. 2014;472(3):953-61.

11. Gunther KP, Lutzner J, Hannemann F, et al. Update on metal-on-metal hip joints. Orthopade. 2013;42(5):373-87.
12. Langton DJ, Joyce TJ, Mangat N, et al. Reducing metal ion release following hip resurfacing arthroplasty. Orthop Clin North Am. 2011;42(2):169-80.

13. MacDonald SJ, Brodner W, Jacobs JJ. A consensus paper on metal ions in metal-on-metal hip arthroplasties. J Arthroplasty. 2004;19(8 Suppl 3):12-6.

14. Hart AJ, Sabah SA, Bandi AS, et al. Sensitivity and specificity of blood cobalt and chromium metal ions for predicting failure of metal-on-metal hip replacement. J Bone Joint Surg Br. 2011;93(10):1308-13.

15. Sidaginamale RP, Joyce TJ, Lord JK, et al. Blood metal ion testing is an effectivescreening tool to identify poorly performing metal-on-metal bearingsurfaces. Bone Joint Res. 2013;2(5):84-95.

16. Thomas MS, Wimhurst JA, Nolan JF, Toms AP. Imaging metal-on-metal hip replacements: the Norwich experience. HSS J. 2013;9(3):247-56.

17. Siddiqui IA, Sabah SA, Satchithananda K, et al. A comparison of the diagnostic accuracy of MARS MRI and ultrasound of the painful metal-on-metal hip arthroplasty. Acta Orthop. 2014;85(4):375-82.

18. Smith J, Lee D, Bali K, et al. Does bearing size influence metal ion levels in large-head metal-on-metal total hip arthroplasty? A comparison of three total hip systems. J Orthop Surg Res. 2014;9:3.

19. De Smet KA, Van Der Straeten C, Van Orsouw M, Doubi R, Backers K, Grammatopoulos G. Revisions of metal-on-metal hip resurfacing: lessons learned and improved outcome. Orthop Clin North Am. 2011;42(2):259-69.

20. Haddad FS, Thakrar RR, Hart AJ, et al. Metal-on-metal bearings: the evidence so far. J Bone Joint Surg Br. 2011;93(5):5729.

21. Matharu GS, Pynsent PB, Dunlop DJ. Revision of metal-onmetal hip replacements and resurfacings for adverse reaction to metal debris: a systematic review of outcomes. Hip Int. 2014;24(4):311-20.

22. Matharu GS, Eskelinen A, Judge A, Pandit HG, Murray DW. Revision surgery of metal-on-metal hip arthroplasties for adverse reactions to metal debris. Acta Orthop. 2018;89(3):278-88. 